\title{
GLAUCOFANA XISTOS DE CANINDÉ-CEARÁ E A GEOSUTURA SENADOR POMPEU
}

\author{
A.R.Almeida, J.A.Nogueira Neto
}

Dentro do estágio atual do conhecimento geológico inerente aos segmentos crustais africano e sul-americano, é aceito que o episódio orogênico Pan-Africano/Brasiliano representam um processo de criação de terrenos oeste-gonduânicos, através de mecanismos colisionais de antigas massas continentais. Durante a última década, pesquisadores que lidam com a geologia do Estado do Ceará têm se deparado com evidências cada vez mais marcantes de uma estruturação geotectônica associada a mecanismos de colisão. Foliações de baixo ângulo caracterizando thrust belt (Pessoa \& Archanjo, 1984), com gradientes metamórficos invertidos (Caby \& Arthaud, 1986), foram observados na região centro-sul e sudoeste do Estado (Independência, Tróia e adjacências). Associações metamáficas e metaultramáficas contendo depósitos cromitíferos e sedimentos oceânicos que ocorrem em Tróia e Novo Oriente, foram caracterizadas quimicamente por Almeida et al. (1984) e Angelli et al. (1993). Os padrões estruturais que definem uma estruturação em napes foram também reconhecidos em outras porções do Estado (Caby \& Arthaud, 1986; Matos Abreu et al., 1989; Gorayeb \& Matos Abreu, 1989).

O magmatismo sincolisional, caracterizado pela ocorrência de granitóides aluminosos associados a migmatitos, apesar de sua abundância no Estado, ainda não receberam a devida atenção. Por outro lado, suites magmáticas Neoproterozóicas representantes do magmatismo cálcio-alcalino tardi-colisional, bem como do magmatismo shoshonítico póscolisional, foram estudadas por Almeida et al., (1984, 1988), Almeida (1987, 1989a, b, 1995) e Torquato et al. (1989).

O metamorfismo, embora pobremente estudado, apresenta caracteristicas barrovianas com variações locais. Condições especiais de alta pressão são dadas isoladamente por paragêneses eclogíticas na região de Cariré, noroeste do Estado, Almeida (1995) e Nogueira Filho \& Legrand (submetido).

Do outro lado do Atlântico, um mecanismo de colisão continental foi invocado para explicar o cinturão Dahomeyano no oeste da África (Burke \& Dewey, 1970) e o cinturão Pharusiano no noroeste da África (Black, 1980). O locus da geosutura entre o cráton Oeste Africano e o cráton Saara-Congo é identificado por uma combinação de massas ofiolíticas ultramáficas e uma anomalia gravitacional positiva conspícua, traçável ao longo da borda oeste do cinturão Pharusiano. A mesma anomalia gravitacional é observável no cinturão Dahomeyano, ao sul, estando associada com lentes de serpentinitos da unidade tectônica Tiele e as massas ultrabásicas ao longo da borda este da unidade tectônica Benim Plain. Os limites das unidades tectônicas mencionadas são mega-zonas de cisalhamento de baixo ângulo, com mergulho para este, cujos prolongamentos atravessam a margem continental africana próximo a

DG, Universidade Federal do Ceará. 
Accra, Ghana.

Durante muito tempo acreditou-se que no lado sul-americano, o limite entre o cráton Arqueano e o cinturão Brasiliano devia ser observado por sob os sedimentos da bacia do Parnaiba, ao longo da porção este do cráton São Luis, que tem sido reconhecido como um fragmento do cráton Oeste Africano (Hurley, 1967). Se a geosutura Pharusiano-Dahomeyano se estende através da margem atlântica da América do Sul e segue a margem sul do cráton São Luís, ela separa os continentes antigos Oeste África ou São Luis do bloco paleocontinental São Francisco (Almeida et al., 1967), estando o Estado do Ceará na porção central desta zona colisional.

Por outro lado, idéias alternativas como por exemplo, a de que a estruturação geológica do Nordeste do Brasil, em particular o Ceará, seria o resultado de colisões de várias microplacas (Brito Neves, com. pes.), não estão fora de questão, mesmo porque existem vários indícios da presença de zonas de sutura em regiões diversas daquelas que foram originalmente proposta por Hurley (1967).

$\mathrm{Na}$ fazenda Pedra Preta, $23 \mathrm{~km}$ a sudoeste de Canindé, p. ex., diques e lentes de rochas com estrutura bandada chamam a atenção por mostrar alternância de camadas brancas e camadas azuis, estas últimas sendo compostas essencialmente por minerais dos grupos do epidoto, lawsonita e glaucofana. Estes últimos ocorrem na forma de delicadas fibras radiais constituindo uma textura em feltro, cujos constituintes exibem um pleocroismo azul lavanda. Ocorrem também na forma de prismas subedrais intimamente associados a ferro-eckermanita, sugerindo um manto glaucofânico sobre este mineral. Dados de química mineral obtidos em microssonda eletrônica da USP, tratados através do MINPET 2.0, indicam que estes anfibólios sódicos encontrados possuem química compativel com glaucofana/ferro-glaucofana. $\mathrm{Fe}+2 \mathrm{e} \mathrm{Fe}+3$ nos anfibólios foram estimados levando em conta uma carga cationnica total igual a 46 e que a soma de $\mathrm{Mg}+\mathrm{Fe}+2+\mathrm{Fe}+3+\mathrm{Ti}+\mathrm{Mn}+\mathrm{Al}+\mathrm{Si}=13$. Plagioclásios com núcleos fortemente alterados manteados por coroas de albita compõem as camadas brancas. Minerais do grupo da granada, prenhita, omfacita, jadeita, margarita e minerais óxidos de ferro e óxidos de manganês são minerais acessórios. A identificação microscópica de minerais supracitados foi respaldada por difração de raios $\mathrm{X}$.

$\mathrm{Na}$ região de Chorozinho, em particular ao longo do leito do rio Choró, são encontradas rochas do fácies eclogito constituidas por granada ss, (Almandina 64, Piropo 19, Grossulária 12 e espessartita 5); clinopiroxênio verde e quartzo, rochas do fácies eclogito transicional ao fácies anfibolito caracterizadas por intercrescimento simplectítico plagioclásio/clinopiroxênio e plagioclásio/anfibólio e rochas do fácies granulito, caracterizada pela paragênese silimanita-granada. Paragêneses transicionais exibem cianita-granada. Nesta região cherts manganesíferos ricos em granada são abundantes. Estes metassedimentos manganesíferos parecem caracterizar a camada 1 da paleocrosta oceânica. Rochas metabásicas metamorfisadas nos fácies eclogito e granulitos são também comuns ao longo da rodovia que liga as cidades de Mombaça e Senador Pompeu.

A caracterização de xistos glaucofânicos no Estado do Ceará tem, portanto, uma importância capital na redefinição dos processos que estruturaram o arcabouço geotectônico no Nordeste do Brasil, elevando a zona de cisalhamento Senador Pompeu à categoria de zona de sutura, ou no minimo, o locus de uma zona de subducção, com idade provavelmente neoproterozóica. 


\section{Referências Bibliográficas}

ALMEIDA, A.R. (1987) Petrologia da Província Subvulcânica de Tauá e Independência-CE. Recife, (Dissertação - Mestrado) - Instituto de Geociências, Universidade Federal de Pernambuco.

ALMEIDA, A.R. (1988) Coroas de reação em rochas gabróides de Tauá-CE. Revista de Geologia, v.1, n.2, p.5-18.

ALMEIDA, A.R. (1988) Petrogênese das rochas peralcalinas de Bom Jesus e Ematuba- CE. Revista de Geologia, v.1, n.2, p.19-35.

ALMEIDA, A.R. (1995) Petrologia e Aspectos Tectônicos do Complexo Granítico QuixadáQuixeramobim - CE. São Paulo, 279p. (Tese - Doutorado) - Instituto de Geociências, Universidade de São Paulo.

ALMEIDA, A.R.; SIAL, A.N.; FERREIRA, V.P. (1984) Petrologia e geoquímica de enxames de diques Cambrianos do Nordeste do Brasil. In: SIMPÓSIO DE GEOLOGIA DO NORDESTE, 11., Atas. SBG-NE, p.60-77.

ALMEIDA, A.F.M.; LEONARDOS, O.H.; VALENÇA, J. (1967) Review on granitic rocks of Northeast South America. In: INTERNATIONAL UNION GEOLOGICAL SCIENCE SYMPOSIUM, Buenos Aires, UNESCO, 1967. 4lp.

ALMEIDA, A.R; SIAL, A.N.; FERREIRA, V.P. (1988) Isótopos de oxigênio em enxames de diques Cambrianos do Ceará. Revista de Geologia, v.1, n.1, p.21-30.

ANGELI, N.; FLEET, M.E.; KINGSTON, D.M.; NOGUEIRA NETO, J.A. (1993) Ir-bearing sperrylite and Pd-bearing hollingwortite in chromitites from Pedra Branca Complex, Ceará, Brazil. In: BRAZILIAN MEETING ON PGE, 1., Brasília, 1993. Extended Abstracts, Brasília, p.44-46.

BLACK, R. (1980) Precambrian of West Africa. Episodes, v.4, p.3-8.

BURKE, K.; DEWEY, J.F. (1970) Orogeny in Africa. In: DESSAUVAGIE, T.F.J.; WHITEMAN, A.J. (Eds.) African Geology. Ibadan, Univ. Press, p.583-608.

CABY, R.; ARTHAUD, M.H. (1986) Major Precambrian nappes of the Brazilian Belt, Ceará, Northeast Brazil. Geology, v.14, p.871-874.

GORAYEB, P.S.S.; MATOS ABREU, F.A.M. (1989) A faixa de alto grau da região de Cariré-CE. In: SIMPÓSIO NACIONAL DE ESTUDOS TECTÔNICOS, 2., Fortaleza, 1989. Atas. Fortaleza, SBG-NE. p.261-264.

HURLEY, P.M.; ALMEIDA, F.F.M.; MELCHER, G.C.; CORDANI, V.G.G.; RAND, J.R.; KAWASHITA, K.; VANDOROS, P.; PINSON, W.H.; FAIRBAIRN, H.W. (1967) Test of continental drift by means of radiometric ages. Science, v.157, p.495-500.

MATOS ABREU, F.A.M.; GORAYEB, P.S.S.; GAMA JÚNIOR, T. (1989) Aspectos tectônicos da região de Martinópole-Massapê-CE. In: SIMPÓSIO NACIONAL DE ESTUDOS TECTÔNICOS, 2., Fortaleza, 1989. Atas. Fortaleza, SBG-NE. p.265-269.

NOGUEIRA NETO, J.A.; LEGRAND, J.M. (no prelo) Geoquímica e Evolução metamórfica da Faixa Granulítica de Cariré (CE). Revista de Geologia.

PESSOA, R.R.; ARCHANJO, C.J. (1984) Tectônica de empurrões na região de Tróia-CE. In: CONGRESSO BRASILEIRO DE GEOLOGIA, 33., Rio de Janeiro, 1984. Anais. Rio de Janeiro, SBG, v.4, p.1721-1728.

TORQUATO, J.R.F.; ALMEIDA, A.R.; SIDRIM, A.C.G.; MARANHÃO, C.M.L.; PARENTE, C.V.; NOGUEIRA NETO, J.A.; ANDRADE FILHO, J.F.; SOUZA, J.V.; ARTHAUD, M.H. (1989) Granitóides do Ceará - Região de Quixadá-Solonópole. Revista de Geologia, v.2, n.1/2, p.143. 